\title{
Reduction of Colour in Treated Wastewater from Textile Industry Using Sawdusts as Bio-sorbents
}

\author{
A.I. Hettige ${ }^{*}$ and M.I.M. Mowjood ${ }^{1}$ \\ Postgraduate Institute of Agriculture \\ University of Peradeniya \\ Sri Lanka
}

\begin{abstract}
Textile industries use dye such as Rhodamine B, Brilliant Red and Reactive Orange for the fabrics. Thus the colour of the effluent even after the normal treatment is not within the standard to discharge into the environment. A study was conducted to identify suitable bio-sorbents and to optimize the conditions for selected bio-sorbent to reduce the colour of treated waste water (TWW) from a textile industry. Sieved and air dried sawdust from Rubber (Hevea brasiliensis), Trincomalee wood (Berrya cordifolia), and Breadfruit (Artocarpus altillis) timber were tested with TWW. Rubber sawdust showed a better performance in colour removal than the sawdust from Trincomalee wood and Breadfruit. In order to optimize the conditions with the rubber sawdust, colour removal efficiency of TWW was measured at different $\mathrm{pH}$, sawdust amount, initial dye concentration and different contact times. Sorption data was modelled by Langmuir and Freundlich adsorption isotherms for each dye; Rhodamine B, Brilliant Red, Reactive Orange. Results showed that the best performances of adsorption of dye into Rubber sawdust was obtained at $5 \mathrm{~g} / \mathrm{L}$ sawdust dosage with 6 minutes contact time up to $0.2 \mathrm{ml}$ of $0.5 \mathrm{M}$ dye concentration under pH 2. Adsorptions of acidic dye (Brilliant Red) and anionic reactive dye (Reactive Orange) followed the Langmuir isotherm. Sorption of cationic dye Rhodamine $B$ was better represented by the Freundlich model. It is recommended to use the sawdust of rubber to remove the colour in wastewater in acidic condition and neutralize the effluent before discharge to the environment.
\end{abstract}

Keywords: Bio-sorbent, colour, sawdust, textile industry, wastewater

\section{INTRODUCTION}

The textile industry consumes a substantial amount of water in manufacturing processes mainly in the dyeing and finishing operations of the plants. The wastewater from textile plants is classified as the most polluting of all the industrial sectors, considering the volume generated as well as the effluent composition (Chequer et al., 2013). The wastewater includes dilute detergent, dilute spent chemicals, trace contaminants, bleach water, unfixed dye, unfixed ink etc. Other than wash water, make up water in utilities, steam, cooling tower water, chilled water, hot water are also combined to form industrial textile wastewater.

Dyes in textile effluent are of concern to the regulators and community due to the appearance. Most coloured effluent problems arise from dyeing with reactive dyes. Heavy

Deprtment of Agricultural Engineering, Faculty of Agriculture, University of Peradeniya, Sri Lanka

Corresponding author: amali.hettige@gmail.com 
metals are associated with the effluents from wool dyeing. With respect to the number and production volumes, azo dyes are the largest group of colourants, constituting 60-70\% of all organic dyes produced in the world (Bafana et al., 2011). The success of azo dyes is due to their ease and cost effectiveness for synthesis as compared to natural dyes, and also their great structural diversity, high molar extinction coefficient, and medium- to-high fastness properties in relation to light as well as to wetness (Bafana et al., 2011). One of the most difficult tasks confronted by the wastewater treatment plants of textile industries is the removal of colour of these compounds, mainly because dyes and pigments are designed to resist biodegradation, such that they remain in the environment for a long period of time. Dyes, which represent a large and important group of synthetic chemicals, are also important water pollutants, present in the effluents of the textile industries. The release of these compounds into the environment is undesirable, not only for aesthetic reasons, but also many azo dyes and their breakdown products are toxic and/or mutagenic.

Some conventional technologies (precipitation, coagulation, flocculation, UV/ozone treatment, electrochemical reduction, biological treatment) may be efficient in the removal of dyes, but their operational costs are very high. Among these methods, adsorption is one of the most economic methods in decolourization of textile effluents because of simple design and operation, availability, non-toxicity, superior removal of pollutants (Suteu et al., 2008). The great advantage of this method is the possibility to use inexpensive and readily available materials with adsorptive and ion exchange properties.

Natural materials that are available in large quantities or certain waste from agricultural operations may have the potential to be used as low cost adsorbents. Large varieties of solid materials have capacity to act as sorbents: synthetic to natural low-cost materials such as activated charcoal, natural zeolites, sphagnum peat, fly ash, ligno-cellulosic materials. Waste materials from industry or agriculture such as sawdust and active or inactive biomass resulted from industrial fermentative technology (food and pharmaceutical industry) are also used as adsorbates. Replacing synthesized compounds, wastewater treatment by sorption onto unconventional natural or biological materials ("green" or "environmental friendly") have recently become the subject of considerable interest (Suteu et al., 2008).

The sawdust, a low cost locally available material and a solid waste, can be used as biosorbent for the removal of contaminant. Sawdust is an abundant by-product composed of fine particles of wood. It is considered as an agricultural waste and a by-product of manufacturing industries. It is readily available in the countryside at zero or negligible price. Sawdust has proven to be a promising effective material for the removal of dyes from wastewaters of many types of pollutants, such as dyes, oil, salts, heavy metals (Baral et al., 2006 and Stankovic et al., 2009).

Effluent from fabric industries are treated using conventional treatment plants. However, the colour of treated wastewater (TWW) has to be reduced to acceptable level. The objective of this study was to identify an appropriate bio-sorbent for colour reduction and optimize the process with the selected bio-sorbent. 


\section{METHODOLOGY}

\section{Preparation of bio-sorbent}

Freely and abundantly available sawdusts in saw mills were considered. Thus saw-dust from rubber (Hevea brasiliensis), breadfruit (Artocarpus altilli), and Trincomalee wood (Berrya cordifolia) were selected for the study. Each sawdust type was air dried and sieved with 1 $\mathrm{mm}^{2}$ mesh. Sawdust $<1 \mathrm{~mm}$ particle size and moisture content between 15 and 20 (W/W\%) were taken for further analysis.

\section{Adsorption study}

At the beginning, suitable sawdust was identified. Then, in order to optimize the process, the effect of $\mathrm{pH}$, zero point charge, amount of sawdust, initial concentration of dye, equilibrium time for adsorption were studied for the selected sawdust as illustrated in Figure 1. The water discharged from a conventional treatment plant from a textile industry (Treated wastewater - TWW) was used in this sorption study. The textile dye, Rhodamine $B$ was used only to study effect of initial dye concentration. Rhodamine B, Brilliant Red, and Reactive Orange were used for isotherm modelling.

\section{Identification of suitable bio-sorbent material}

Suete et al., (2008) have reported that the better colour removal in textile wastewater can be obtained with the saw dust dosage more than $10 \mathrm{gL}^{-1}$ at $\mathrm{pH}$ value $1-2$ for anionic dyes and 5 -9 for cationic dyes. Therefore, TWW was adjusted to $\mathrm{pH} 5$ and added $10 \mathrm{gL}^{-1}$ of sawdust of each bio-sorbent; rubber, breadfruit and Trincomalee wood (Figure 1). The mixture was stirred for 10 minutes. Then the suspensions were filtered through filter paper (Whatman 47 $\mathrm{mm}$ ). Colour of each filtrate and TWW were measured using spectrophotometer (Spectro Direct -Lovibond, UK). Hanna $\mathrm{pH}$ meter was used to measure $\mathrm{pH}$.

\section{Effect of pH on adsorption}

Preliminary selection test conducted with replication ( 3 runs)showed that rubber sawdust has comparatively higher sorption capacity than other two types. In order to study the effect of $\mathrm{pH}$ on rubber sawdust, the $\mathrm{pH}$ of TWW were adjusted from $\mathrm{pH} 1$ to 12 using $1 \mathrm{M} \mathrm{NaOH}$ and $1 \mathrm{M} \mathrm{H}_{2} \mathrm{SO}_{4}$. Then, $250 \mathrm{ml}$ of TWW sample was mixed with $2.5 \mathrm{~g}$ of rubber sawdust and stirred for 10 minutes (Figure 1). Suspensions were filtered through Whatman $47 \mathrm{~mm}$ white filter paper. Colour of each filtrate was measured.

\section{Zero point of charge}

$0.01 \mathrm{M} \mathrm{NaCl}$ solution was prepared and its initial $\mathrm{pH}$ was adjusted from $\mathrm{pH} 1$ to 12 using 1 $\mathrm{M} \mathrm{NaOH}$ and $1 \mathrm{M} \mathrm{H}_{2} \mathrm{SO}_{4}$. Then $50 \mathrm{ml}$ of $0.01 \mathrm{M} \mathrm{NaCl}$ sample was collected to $250 \mathrm{ml}$ Erylenmeyers flask and $2.5 \mathrm{~g}$ of rubber sawdust was added to each solution. Flasks were kept for $48 \mathrm{~h}$ and $\mathrm{pH}$ was measured using $\mathrm{pH}$ meter(Figure 1). 
1. Identification

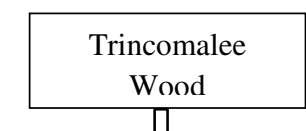

Saw dust - $10 \mathrm{~g} / \mathrm{l}$, $\mathrm{pH} 5$

2. $\mathrm{pH}$ test
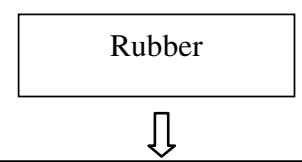

Saw dust $-10 \mathrm{~g} / \mathrm{l}$, $\mathrm{pH} 5$

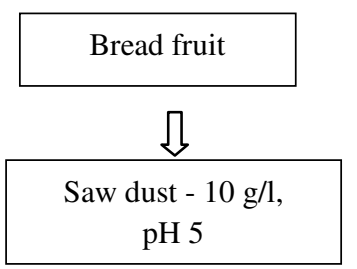

3. Zero point of charge

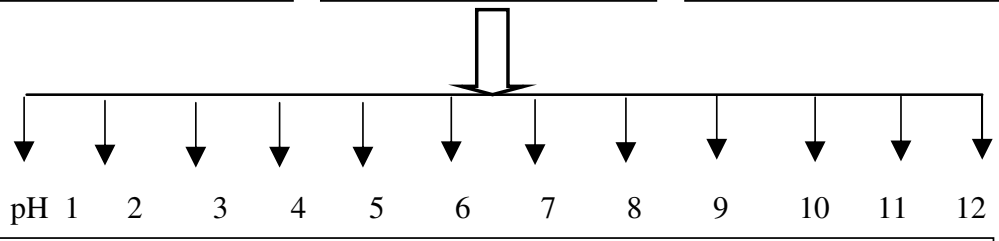

TWW $-250 \mathrm{ml}$, Rubber saw dust $-2.5 \mathrm{~g}$, Retention time $10 \mathrm{~min}$

4. Sawdust (g)

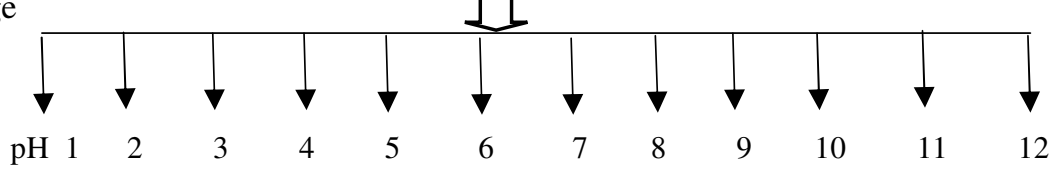

$1 \mathrm{M} \mathrm{NaOH} \& 1 \mathrm{M} \mathrm{H}_{2} \mathrm{SO}_{4}$, TWW - $250 \mathrm{ml}$, Rubber saw dust - $2.5 \mathrm{~g}$, Retention time $48 \mathrm{~h}$

5. Initial Rhodamine B dye (ml)
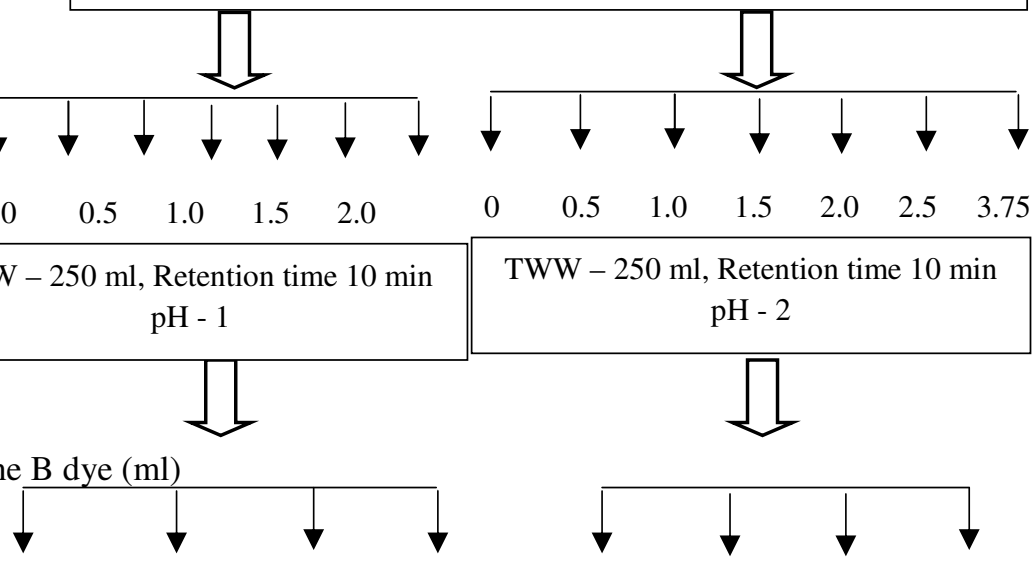

$\begin{array}{llllllllllll}0 & 0.5 & 1.0 & 1.5 & 2.0 & 0 & 0.5 & 1.0 & 1.5 & 2.0 & 2.5 & 3.75\end{array}$

TWW - $250 \mathrm{ml}$, Retention time $10 \mathrm{~min}$ $\mathrm{pH}-1$

TWW - $250 \mathrm{ml}$, Retention time $10 \mathrm{~min}$ $\mathrm{pH}-2$
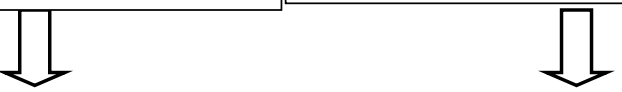

\section{$\begin{array}{llll}0 & 0.1 & 0.2 & 0.3\end{array}$}

TWW - $250 \mathrm{ml}$, Retention time 10 $\min$,

Saw dust - $2.5 \mathrm{~g}, \mathrm{pH}-1$

6. Time of equilibrium ( $\mathrm{min})$

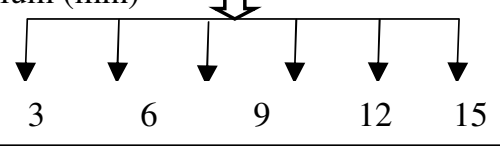

TWW $-250 \mathrm{ml}$, Saw dust $-2.5 \mathrm{~g}, \mathrm{pH}-1$

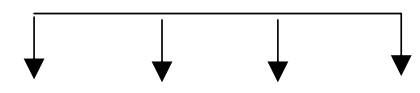

$\begin{array}{llll}0 & 0.1 & 0.2 & 0.3\end{array}$

TWW - $250 \mathrm{ml}$, Retention time $10 \mathrm{~min}$,

Saw dust - $2.5 \mathrm{~g}, \mathrm{pH}-2$

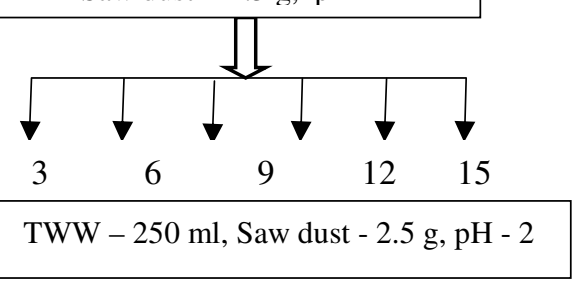

Fig. 1. Flow chart of the sorption experiment 


\section{Effect of amount of sawdust on adsorption}

From the above test, $\mathrm{pH} 1$ and $\mathrm{pH} 2$ were selected as the most suitable $\mathrm{pH}$ for adsorption with rubber sawdust. The $\mathrm{pH}$ of $\mathrm{TWW}(250 \mathrm{ml})$ was adjusted for both $\mathrm{pH} 1$ and $\mathrm{pH} 2$, separately and 0 (control), $0.50,1.00,1.50,2.00,2.50,3.75 \mathrm{~g}$ of rubber sawdust was added (Figure 1). The TWW without addition of sawdust but with $\mathrm{pH}$ adjustment was used as control for determining the removal efficiency. Then suspensions were filtered through Whatman $47 \mathrm{~mm}$ white filter paper. Subsequently colours of each filtrate were measured.

\section{Effect of initial dye concentration on adsorption}

Most suitable $\mathrm{pH}$ and sawdust amount for adsorption with rubber sawdust were selected. Then, 0 (control), $0.1,0.2,0.3 \mathrm{ml}$ of $0.5 \mathrm{M}$ Rhodamine $\mathrm{B}$ dye solution were added to $\mathrm{pH}$ adjusted TWW sample $(250 \mathrm{ml})$ and stirred for 10 minutes (Figure 1). Suspensions were filtered through Whatman $47 \mathrm{~mm}$ white filter paper. Colours of each filtrate were measured.

\section{Effect of contact time on adsorption}

The $\mathrm{pH}$ of TWW was adjusted to $\mathrm{pH} 1$ and 2 using $1 \mathrm{M} \mathrm{H}_{2} \mathrm{SO}_{4}$ samples $(250 \mathrm{ml})$ were mixed with $2.5 \mathrm{~g}$ of rubber sawdust. Suspensions were collected separately, after 3, 6, 9, 12, 15 and $18 \mathrm{~min}$ and filtered through Whatman $47 \mathrm{~mm}$ white filter paper (Figure 1). Colours of each filtrate were measured.

\section{Colour removal performance}

Colour of the filtrates obtained from the above experiments was measured using Spectrophotometer (Spectro Direct - Lovibond, UK) at $432 \mathrm{~nm}, 525 \mathrm{~nm}$, and $620 \mathrm{~nm}$ wave lengths to represent yellow, red and blue colour, respectively. The colour removal efficiency (R) of the sawdust was evaluated using Equation 1.

$$
\mathrm{R}(\%)=\left[\left(\mathrm{C}_{0}-\mathrm{C}\right) / \mathrm{C}_{0}\right] .100
$$

where, $C_{0}$ and $C$ are the initial and equilibrium colour values, respectively.

\section{Adsorption isotherm models}

Three dyes, Rhodamine B, Brilliant Red, and Reactive Orange were used to model the adsorption. Freundlich and Langmuir isotherms models were fitted using linear Equations 2 and 3 (Suteu et al., 2008).

Freundlich isotherm: $\quad \log \mathrm{q} \quad=\log \mathrm{K}_{\mathrm{F}}+1 / \mathrm{n} \log \mathrm{C}$

Langmuir isotherm: $\quad 1 / \mathrm{q} \quad=1 / \mathrm{q}_{0}+1 /\left(\mathrm{K}_{\mathrm{L}} \cdot \mathrm{q}_{0}\right) \cdot 1 / \mathrm{C}$

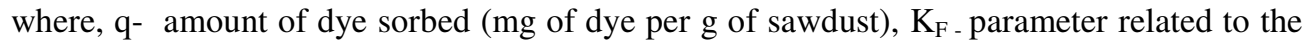
adsorption capacity, $\mathrm{n}$ - measure of sorption intensity (a favourable sorption corresponds to a value of $1<\mathrm{n}<10$ ), $\mathrm{K}_{\mathrm{L}}$ - Langmuir constant, and $\mathrm{q}_{0}$ - maximum value of sorption capacity (corresponding to complete monolayer coverage) and $\mathrm{C}$ - equilibrium colour concentration. 
The Freundlich constants $\left(\mathrm{K}_{\mathrm{F}}\right.$ and $\left.\mathrm{n}\right)$, and Langmuir constant $\left(\mathrm{q}_{0}\right.$ and $\mathrm{K}_{\mathrm{L}}$ ) were calculated by plotting $\log q$ vs. $\log C$ and $1 / q$ vs. $1 / C$, respectively (Suteu et al., 2008).

\section{RESULTS AND DISCUSSION}

\section{Identification of suitable bio-sorbent material}

Initial $\left(\mathrm{C}_{0}\right)$, equilibrium $(\mathrm{C})$ values for colour and the removal efficiency $(\mathrm{R} \%)$ with each sawdust type are shown in Table 1. The values obtained from the spectrometer for each colour, not the concentration are shown in Table 1. This initial test was done at $\mathrm{pH} 5$ as selected from literature (Suteu et al., 2008). Rubber sawdust showed positive and higher colour removal percentages for all three colours; yellow, red and blue compared to Trincomalee wood and Breadfruit. The negative removal percentages from Trincomalee wood and breadfruit may have been due to colour release from the sawdust. Therefore, the rubber sawdust was selected for detail studies.

Table 1. Adsorption performance with various sawdust types at pH 5

\begin{tabular}{lccccccc}
\hline & \multicolumn{1}{c}{$\begin{array}{c}\text { Without } \\
\text { Sawdust }\end{array}$} & \multicolumn{7}{c}{ With sawdust } \\
\hline Colour & TWW $\left(\mathrm{C}_{\mathrm{o}}\right)$ & $\mathrm{TW}(\mathrm{C})$ & $\begin{array}{c}\mathrm{R} \% \\
(\mathrm{TW})\end{array}$ & $\begin{array}{l}\mathrm{RB} \\
(\mathrm{C})\end{array}$ & $\begin{array}{c}\mathrm{R} \% \\
(\mathrm{RB})\end{array}$ & $\mathrm{BF}(\mathrm{C})$ & $\begin{array}{l}\mathrm{R} \% \\
(\mathrm{BF})\end{array}$ \\
\hline $\begin{array}{l}\text { Yellow } \\
(436 \mathrm{~nm})\end{array}$ & 2.51 & 2.93 & -16.73 & 2.41 & 3.98 & 3.02 & -20.32 \\
$\begin{array}{l}\text { Red } \\
(525 \mathrm{~nm})\end{array}$ & 2.33 & 2.31 & 4.66 & 2.10 & 9.88 & 2.45 & -5.15 \\
$\begin{array}{l}\text { Blue } \\
(620 \mathrm{~nm})\end{array}$ & 1.02 & 1.00 & 1.96 & 0.97 & 4.90 & 0.99 & 2.94 \\
\hline \begin{tabular}{l} 
TW - Trincomalee wood, RB - Rubber, BF - Bread Fruit \\
\hline
\end{tabular}
\end{tabular}

TW - Trincomalee wood, RB - Rubber, BF - Bread Fruit

\section{Effect of pH on adsorption}

The effect of initial $\mathrm{pH}$ on the bio-sorption was examined and the results are shown in Figure 2. Removal of colour decreased with the increase in $\mathrm{pH}$. Higher removal was observed in lower $\mathrm{pH}$ values. Blue colour removal was higher than the red and yellow colour by the rubber sawdust. The negative removal percentages observed in higher $\mathrm{pH}$ values may be due to the release of colour from the sorbent which was not tested in this study. Khattri and Singh (2012) reported that the change in $\mathrm{pH}$ affects the adsorptive process through dissociation of functional groups of the adsorbate and the adsorbent. This removal percentage at $\mathrm{pH} 5$ is not comparable with the removal performance at the initial study for rubber sawdust since the initial concentration varies in both tests. The effect of initial dye concentration will be discussed in the subsequent section. 


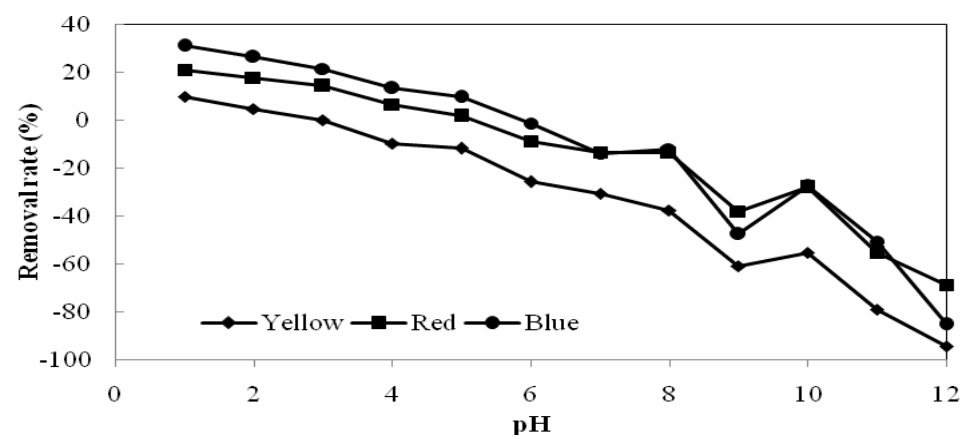

Fig. 2. Adsorption efficiency and pH variation with rubber sawdust

Point of Zero charge was found to be 6.7. Removal efficiency was more favourable in from $\mathrm{pH} 1$ to 3, which was lower than $\mathrm{pH}$ of Point of Zero charge as the dyes responsible for yellow, red and blue colour belong to anionic category.

\section{Effect of amount of sawdust on adsorption}

Figure 3 shows the percentage of colour removal with different dosage of rubber sawdust at $\mathrm{pH} 1$ and $\mathrm{pH}$ 2. The removal rate increased with the increasing sawdust dosage due to the availability of higher number of sorption sites. The saturated level was found as $2.5 \mathrm{~g}$ dosage in $250 \mathrm{ml}$ TWW in both $\mathrm{pH}$ values.
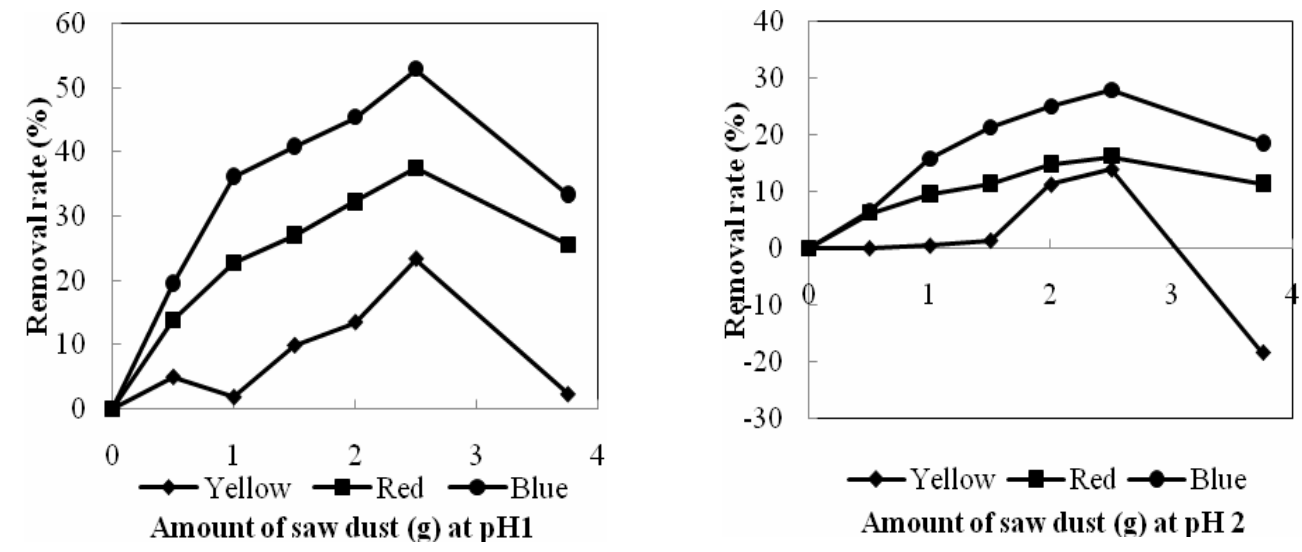

Fig. 3. Dosage of sawdust on adsorption efficiency

\section{Effect of initial dye concentration on adsorption}

Adsorption efficiency slightly increased with increased dye concentration for both $\mathrm{pH}$ (Figure 4). The performance in $\mathrm{pH} 1$ was better compared to $\mathrm{pH} 2$. Adsorption sites were saturated with certain level of dye, and remained dye molecules added extra colour to the solution. Therefore, gradually the colour increased with increasing dye concentration in TWW. 


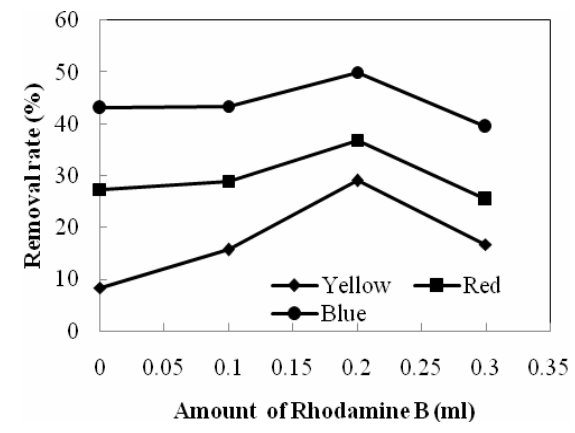

pH 1

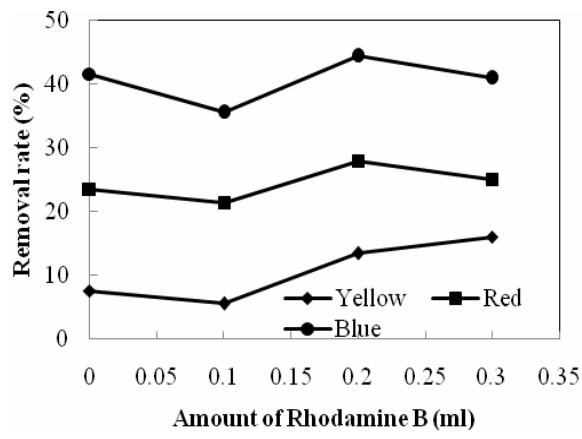

pH 2

Fig. 4. Removal performance with different initial dye concentration

\section{Effect of contact time on adsorption}

Figure 5 shows the removal rates with time at $\mathrm{pH} 2$. The removal of dyes were fast at initial stages of contact period and then, amounts of dye absorbed increased slowly near the equilibrium as the adsorption rate decreased with time as all most all the adsorption sites were filled with dye particles at 6 min.

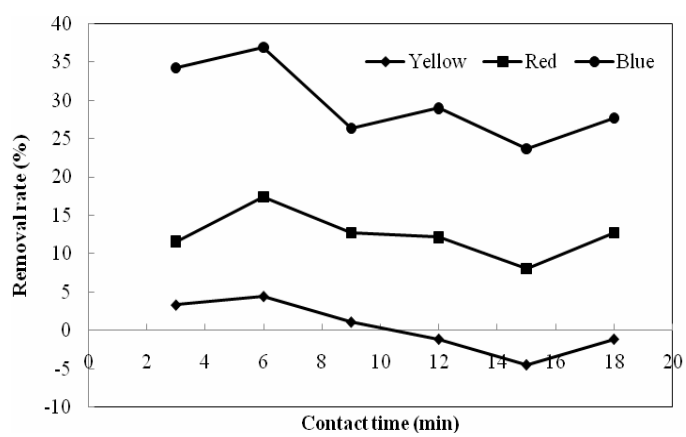

Fig. 5. Removal efficiency with contact time at $\mathbf{p H} 2$

\section{Development of adsorption isotherm}

Langmuir and Freundlich isotherms for three dyes, Rhodamine B, Brilliant Red, and Reactive Orange were developed and shown in Figures 6 to 11. The isotherm parameters are shown in Table 2. Adsorption of cationic dye Rhodamine B was better represented by the Freundlich model, indicating a heterogeneous adsorption surface, with sorption sites of different energies and availability. The adsorption of acidic dye, Brilliant Red and anionic reactive dye, Reactive Orange were followed the Langmuir isotherm, indicating the formation of monolayer coverage of dye molecules at the external surface of the sawdust. 


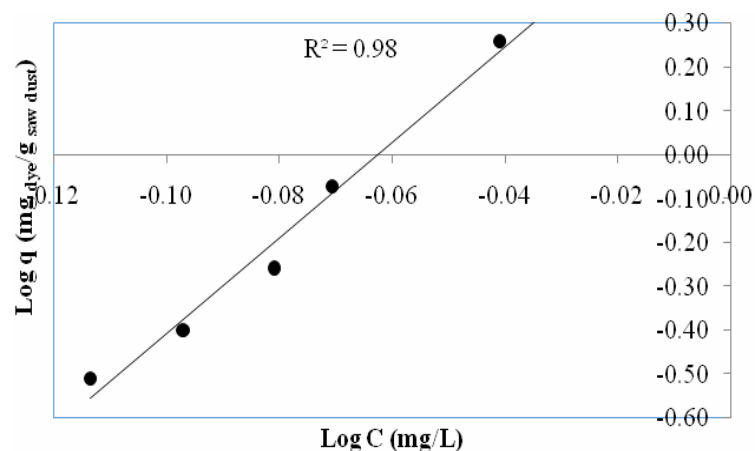

Fig. 6. Freundlich isotherm for Rhodamine B

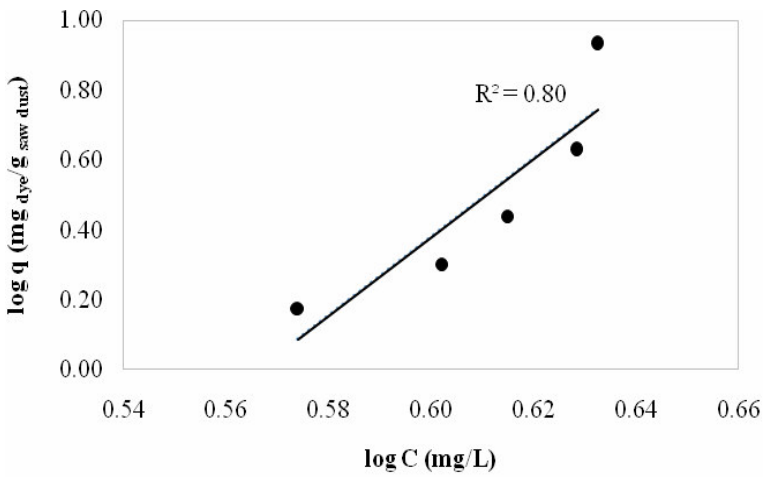

Fig. 7. Freundlich isotherm for Brilliant Red

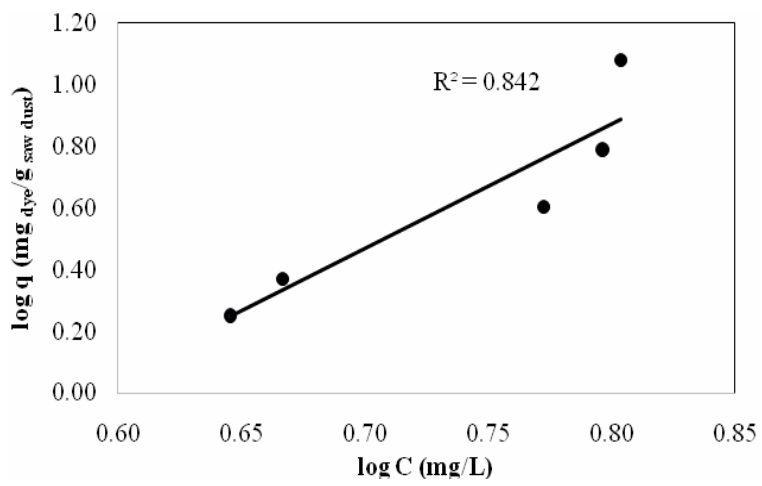

Fig. 8. Freundlich isotherm for Reactive Orange 


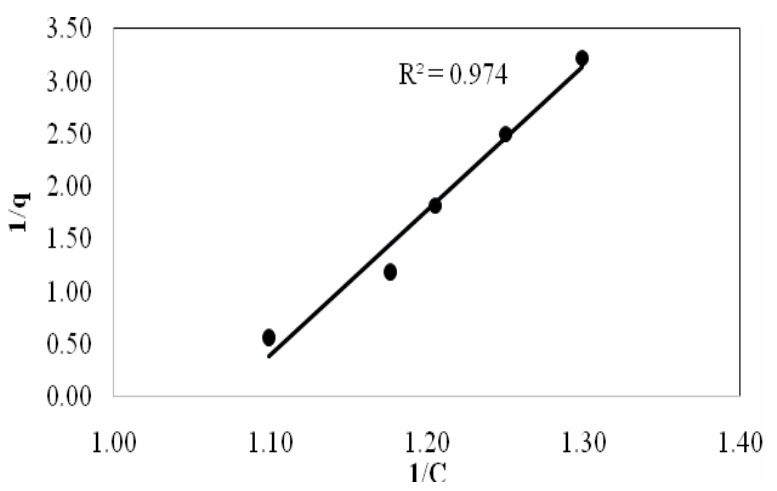

Fig. 9. Langmuir Isotherms for Rhodamine B

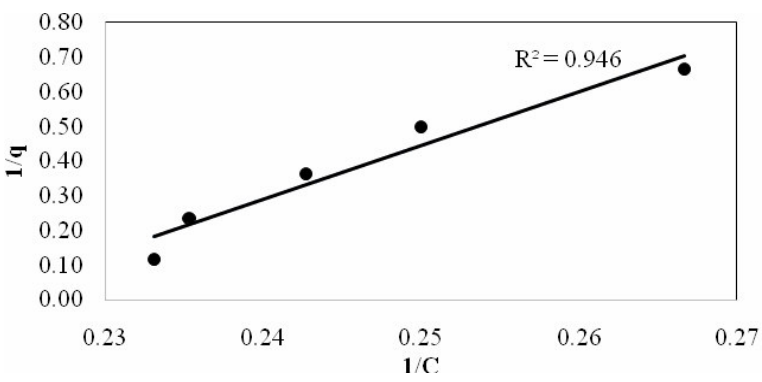

Fig. 10. Langmuir Isotherms for Brilliant Red

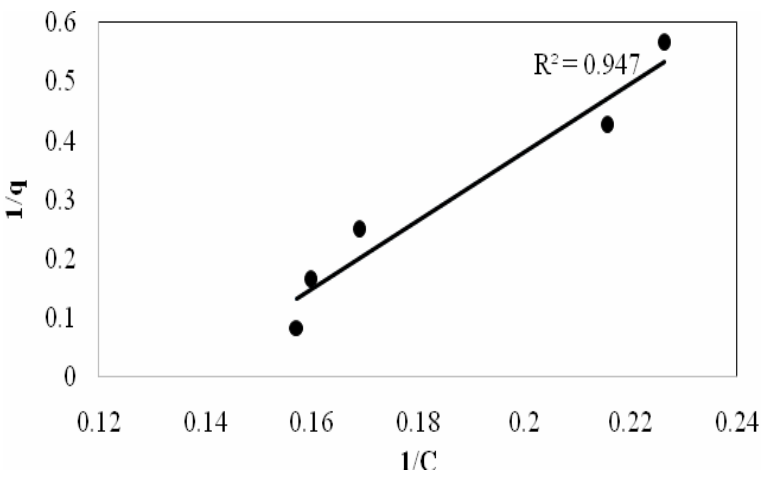

Fig. 11. Langmuir Isotherms for Reactive Orange

Table 2. The isotherms parameters for dyes onto rubber sawdust

\begin{tabular}{lcccccc}
\hline \multirow{2}{*}{\multicolumn{1}{c}{ Dye }} & \multicolumn{3}{c}{ Freundlich Isotherm } & \multicolumn{3}{c}{ Langmuir Isotherm } \\
\cline { 2 - 7 } & $\mathbf{K}_{\mathbf{F}}$ & $\mathbf{n}$ & $\mathbf{R}^{\mathbf{2}}$ & $\mathbf{K}_{\mathbf{L}}$ & $\mathbf{n}$ & $\mathbf{R}^{\mathbf{2}}$ \\
\hline Rhodamine B & 0.6832 & 0.0917 & 0.98 & 0.0725 & 0.9338 & 0.98 \\
Brilliant Red & 6.37 & 0.0889 & 0.80 & 0.0644 & 1.053 & 0.95 \\
Reactive Orange & 2.835 & 0.2463 & 0.77 & 0.1705 & 0.3878 & 0.95 \\
\hline
\end{tabular}




\section{CONCLUSION}

Rubber (Hevea brasiliensis), sawdust performed better compared with other two wood types; Trincomalee wood (Berrya cordifolia), breadfruit (Artocarpus altillis) for removal of colour in treated wastewater from a textile industry. Best performances of removal of colour into Rubber sawdust was obtained at $5 \mathrm{~g} / \mathrm{L}$ sawdust dosage with 6 minutes contact time up to $0.2 \mathrm{ml}$ of $0.5 \mathrm{M}$ dye concentration under $\mathrm{pH} 2$. The sorption can be adequately modelled by the Langmuir and Freundlich adsorption isotherms. Brilliant Red and Reactive Orange were followed the Langmuir isotherm while Rhodamine B was better represented by the Freundlich model. It is recommended to remove the colour using rubber sawdust in acidic condition and neutralize the effluent before discharging.

\section{REFERENCES}

Bafana, A., Devi, S. and Chakrabart, T. (2011). Azo dyes: past, present and the future. Environmental Reviews. 19, 350 - 370.

Chequer, D., Ferraz, A. and Oliveira, R. (2013). Textile Dyes: Dyeing Process and Environmental Impact; Eco-Friendly Textile Dyeing and Finishing. InTech., 152 - 176.

Khattri S.D and Singh M.K (2012) Use of sagaum sawdust as an adsorbent for the removal of crystal violet Dye from simulated waste water. Environ. Prog. \& Sus. Ene., 31(3): 435442.

Stankovic, V., Bozic, D., Gorgievski. M. and Bogdanovic, G. (2009). Heavy Metal Ions Adsorption from Mine Waters By Sawdust, Chemical Industry \& Chemical Engineering Quarterly. 4, 237-249.

Suteu, D., Bilba, D., Zaharia, C. And Popescu, A (2008). Removal of Dyes From Textile Wastewater by Sorption Onto Ligno-Cellulosic Materials. Scientific Study \& Research. IX (3), 293 - 302. 